\title{
Review Article \\ Remote Sensing of Aboveground Biomass in Tropical Secondary Forests: A Review
}

\author{
J. M. Barbosa, ${ }^{1}$ E. N. Broadbent, ${ }^{2}$ and M. D. Bitencourt ${ }^{1}$ \\ ${ }^{1}$ Department of Ecology, Institute of Biosciences, University of São Paulo, 05508-090 São Paulo, SP, Brazil \\ ${ }^{2}$ Sustainability Science Program, Kennedy School of Government, Harvard University, Cambridge, MA 02138, USA
}

Correspondence should be addressed to J. M. Barbosa; jomarmbarbosa@gmail.com

Received 3 December 2013; Revised 1 February 2014; Accepted 12 February 2014; Published 23 March 2014

Academic Editor: Guy R. Larocque

Copyright (C) 2014 J. M. Barbosa et al. This is an open access article distributed under the Creative Commons Attribution License, which permits unrestricted use, distribution, and reproduction in any medium, provided the original work is properly cited.

\begin{abstract}
Tropical landscapes are, in general, a mosaic of pasture, agriculture, and forest undergoing various stages of succession. Forest succession is comprised of continuous structural changes over time and results in increases in aboveground biomass (AGB). New remote sensing methods, including sensors, image processing, statistical methods, and uncertainty evaluations, are constantly being developed to estimate biophysical forest changes. We review 318 peer-reviewed studies related to the use of remotely sensed AGB estimations in tropical forest succession studies and summarize their geographic distribution, sensors and methods used, and their most frequent ecological inferences. Remotely sensed AGB is broadly used in forest management studies, conservation status evaluations, carbon source and sink investigations, and for studies of the relationships between environmental conditions and forest structure. Uncertainties in AGB estimations were found to be heterogeneous with biases related to sensor type, processing methodology, ground truthing availability, and forest characteristics. Remotely sensed AGB of successional forests is more reliable for the study of spatial patterns of forest succession and over large time scales than that of individual stands. Remote sensing of temporal patterns in biomass requires further study, in particular, as it is critical for understanding forest regrowth at scales useful for regional or global analyses.
\end{abstract}

\section{Introduction}

Secondary and disturbed forests comprise roughly $30-50 \%$ of the area covered by tropical forests [1-4]. These forests play important roles as habitats for animal and plant species [5-7] and store significant amount of carbon per unit area [8]. Secondary forests emerge following natural or human disturbances, such as clearing, selective logging, introduction of invasive species, storms, or wild fires. Forest succession is a natural response to these disturbances and occurs at varying rates and in different directions, as indicated through species composition and forest structure, depending on environment conditions [9]. Changes in structure and species composition during forest succession typically result in substantial increases in aboveground biomass [10, 11]. Thereby spatial and temporal changes in aboveground biomass (AGB) can be useful indicator of the velocity and direction of the forest succession and patterns of AGB distribution and change through time can help to understand how forest structure is related to the natural environmental conditions $[12,13]$ and global carbon cycle [14].

The use of continuous forest metrics obtained using remote sensing (RS) data, for example, aboveground biomass, tree diameter, canopy height, and canopy closure, enables improved characterization of the forest [15] and allows an improved understanding of the ecological drivers behind land cover dynamics [16]. However, challenges exist to estimate biophysical data via available remote sensing technologies, such as optical, radar, and LiDAR data, which form the main tools capable of estimating forest AGB [12, 17-19]. One issue is due to the varying spatial, temporal, radiometric, and spectral resolutions unique to each sensor system, resulting in different advantages and disadvantages to AGB estimation $[20,21]$.

The use of estimated forest biomass in ecology depends on the cost-benefit relationship that includes image accessibility, availability of image processing techniques, and data confidence. The available literature provides an overall view of RS 
TABLE 1: Major issues discussed in the reviewed references and the information derived from the aboveground biomass (AGB) estimation by using remote sensing data.

\begin{tabular}{|c|c|c|}
\hline Topic & Information derived & Reference \\
\hline Forest regrowth & $\begin{array}{l}\text { (i) Identifying forest regenerating processes using temporal AGB } \\
\text { comparison } \\
\text { (ii) Forest structure and AGB changing across forest successional } \\
\text { gradient } \\
\text { (iii) Secondary forest detection }\end{array}$ & {$[28,29,37,38,88,104-106]$} \\
\hline $\begin{array}{l}\text { Human impact on forest } \\
\text { biomass }\end{array}$ & $\begin{array}{l}\text { (i) AGB differences due to disturbance regimes } \\
\text { (ii) Effect of invasive tree species on the stored AGB and forest } \\
\text { structure }\end{array}$ & {$[26,28,49,86,102]$} \\
\hline $\begin{array}{l}\text { Forest responses to } \\
\text { ecological conditions }\end{array}$ & $\begin{array}{l}\text { (i) AGB differences between vegetation physiognomies } \\
\text { (ii) Forest structure differences related to topoedaphic gradients, } \\
\text { climatic conditions, or past land use }\end{array}$ & {$[12,13,53,73,94,104]$} \\
\hline $\begin{array}{l}\text { Carbon sink, source, and } \\
\text { storage }\end{array}$ & $\begin{array}{l}\text { (i) Carbon sequestration } \\
\text { (ii) Carbon amount before specific human impact } \\
\text { (iii) Identifying management action that can improve carbon storage }\end{array}$ & {$[12,26,29,30,102,106-111]$} \\
\hline Modeling evaluation & $\begin{array}{l}\text { (i) Testing modeling approach } \\
\text { (ii) Image processing techniques } \\
\text { (iii) Influence of different spatial scale } \\
\text { (iv) Simulation approach }\end{array}$ & $\begin{array}{l}{[17,18,30,37,41,78,87,88,98,102,} \\
112-121]\end{array}$ \\
\hline Sensor evaluation & $\begin{array}{l}\text { (i) Testing the performance of specific satellite data to estimate } \\
\text { biomass and forest structure } \\
\text { (ii) Testing the AGB accuracy between successional stages } \\
\text { (iii) Testing performance of specific satellite data to temporal } \\
\text { comparison }\end{array}$ & $\begin{array}{l}{[28,50,104,105,107,111-} \\
113,116,118,121-131]\end{array}$ \\
\hline
\end{tabular}

on forest biomass estimation $[20,21]$ and evaluates specific sensors and techniques [19]. However, an integrated effectiveness evaluation of how the AGB estimated with RS data can be used to study the progress of the forest succession and the secondary forest characteristics that interfere in the biomass estimation is missing. Therefore, there is a need for a critical review covering the advantages and limitations of the use of remotely sensed AGB in the evaluation of drivers and paths of the forest succession. In this review we discuss how remote sensing of forests biomass helps to identify forest successional patterns. Our specific objectives are (a) to discuss subtle characteristics of secondary forests that challenge the use of remotely sensed AGB estimations in forest succession studies, (b) to summarize the most frequent ecological inferences discussed and methods used in the literature, and (c) to evaluate the implications of methodological and technological issues in the AGB estimation. We first analyze the potential use of remotely sensed AGB estimations as an ecological variable and then discuss the implications for studies of forest succession. We then summarize the ecological issues mentioned in and the methodological characteristics of the selected studies. We conclude with a discussion of the implications of the findings and highlight opportunities for future investigation.

\section{Database}

Relevant journal articles were found by using keyword searches in the Web of Science and Scopus Databases (accessed in January 2014) and by looking through the reference lists of previous narrative reviews $[16,19,20]$. All searches included the words "tropical forest," "aboveground (or above ground or above-ground) biomass or carbon stock," and "remote sensing" (or "sensed"). Our database selected by the keyword searches consisted of 318 articles and reviews. We found a continuous increase on the number of publications about biomass and carbon stock on tropical forests over the last 29 years (Figure 1). In addition, the higher number of published articles in the last 5-8 years may be related to the increased global interest on climate change. Research institutions from the United States, Brazil, United Kingdom, Germany, and France published most of these articles (Figure 2). The selected articles were published in 101 journals; however, $23 \%$ of them were published only in two journals: "Remote Sensing of Environment" and "International Journal of Remote Sensing."

This total database was used to identify the main ecological questions dealt with in the literature. The studies selected by our literature search discussed different ecological problems, including biological invasions, carbon sources and sinks, conservation status, habitat suitability, technical management comparisons, and biomass map elaboration (Table 1). These subjects were discussed in the present review because each is closely related to the forest succession process.

We refined our final database using the new following criteria: (a) the search words had to be reported either in the title, abstract, author keywords, or plus keywords; and (b) the aboveground biomass estimation had to be performed using biophysical structure (i.e., length, diameter, and crown 


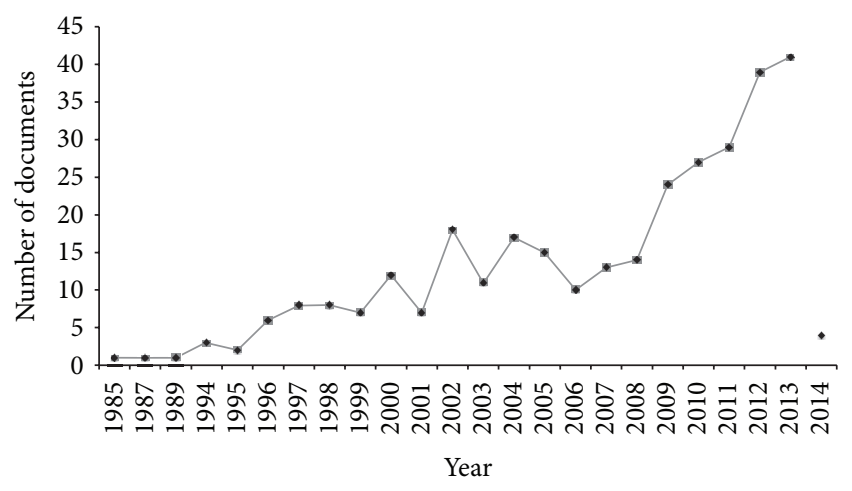

FIGURE 1: Number of articles published over the last 29 years.

size) and remote sensing data. Our final database consisted of 50 articles, which all met the refined criteria and directly or indirectly discuss forest succession patterns and processes. Figure 3 shows the geographic location and spatial resolution of all selected studies. The studies were highly concentrated on Brazilian Amazon, Costa Rica, and Borneo and many of the papers shared the same studied location to collect field data. Approximately, $50 \%$ of these studies were done by institutions located outside the studied country.

\section{Estimated Aboveground Biomass as a Variable in Forest Succession Studies}

Forest patches regrowth from initial to mature condition by forest succession processes [22]. The opposite way, from mature to initial forest stages, also occurs due to forest disturbances in a direct (i.e., clear cut, selective logging) or indirect way (i.e., edge effect in fragmented landscapes) [23-25]. The progress and regress of forest succession result in continuous modifications in species composition and biophysical features. Successively, there is a replacement of species, local environmental changes, and tree growth or increased mortality. Thereby, many studies investigate how fast the velocity of the forest regeneration is [22], how invasive species change the regrowth tendency [26], what the main environmental features determining the direction of the forest succession are [13], or what the level of the carbon storage in different forest stages is [27].

Historically, these questions have been addressed by ground-based surveys, which are frequently sparsely sampled, inventoried at a small scale, and time consuming [28]. Remote sensing technology adds new possibilities for analysis, allowing obtaining data from inaccessible areas using satellite images, which can reduce biases caused by nonrandom plot locations. Satellite images have been largely used to map forest recovery by forest/nonforest maps or successional stand classifications (initial, advanced stages). However, biomass maps obtained from RS data can be used to identify forest succession patterns because AGB integrates important forest structure information associated with forest regrowth or disturbances, such as tree height, diameter, number of trees by area, and wood density (Figure 4), which can be measured and validated in the field.
3.1. Dynamics of $A G B$ during Forest Regrowth from Field and RS Measurements. In tropical forests, young fallows show biomass increases ranging from 1 to $15 \mathrm{Mg} \mathrm{ha}^{-1} \mathrm{yr}^{-1}$ after short-term shifting cultivation $[10,27,29,30]$. A mean biomass increment of $5.3 \mathrm{Mg} \mathrm{ha}^{-1} \mathrm{yr}^{-1}$ has been documented in Atlantic rainforest over a 22-year study of undisturbed forest plots [31]. Thus, secondary forests can rapidly grow up to $100 \mathrm{Mg} \mathrm{ha}^{-1}$ of $\mathrm{AGB}$ or less than $20 \mathrm{Mgha}^{-1}$ within 20 years after land abandonment. The rate of regrowth depends on the availability of seed propagules, vegetation type, environmental conditions, site productivity, intensity of the past land use, and/or human intervention [32]. In tropical forest regrowth, leaf AGB tends to increase for 20 years and wood AGB increases for 40 years before stabilizing [10]. These time periods seem short when compared to some modeling estimations and field observations that have indicated that the tropical forest needs approximately $80-160$ years to reach the mature stage ( $90 \%$ of similar species) [33], although Liebsch et al. [34] found an increase of approximately $57 \%$ in species richness over 25 years of forest regrowth in the Brazilian Atlantic Forest. During regrowth, the species richness and the abundance of fauna also increase rapidly and can recover in the first 10-20 years for animals that are not dependent on late-stage plant species [35].

The challenge is to obtain reliable estimates of AGB associated with regrowth using temporal remotely sensed data. Although landscape scale land cover dynamics have been accurately assessed through RS using classification schemes, such as forest/nonforest (e.g., [36]), the study of forest regrowth using continuous variables, such as AGB, can provide new perspectives on regeneration patterns. The ability to track AGB through time enables the assessments of the directional changes in forest dynamics [16]. Although limitations to RS estimation of temporal variation in AGB exist, such as those found by [37] who showed that they overestimated forest regrowth rates as a result of forest fires and a severe El Niño drought before the image dates and uncorrected atmospheric effects; a growing number of studies are developing and implementing methodological techniques to minimize such uncertainties [38-41].

The spatial and temporal evaluation of forest regrowth patterns is also an important issue. Areas belonging to the same region may show different forest area increase as a consequence of differences in human demography and industrialization $[42,43]$. Moreover, the losses (by degradation) and accumulations (by forests regrowth) of biomass may change without a change in forest area [44]. The structure and change dynamics of an old-growth tropical forest was studied by Kellner et al. [38]. In 8.5 years, the authors found an equal number of positive and negative transitions of mean canopy height estimated by using LiDAR data, indicating steadystate dynamics of disturbance and regeneration. Therefore, unknown tendencies in forest regrowth patterns associated with AGB changes can appear at different time and spatial ranges of analysis.

Forest regrowth has also been identified in remote sensing studies by using forest age $[30,45]$ or successional stand classes [46, 47]. However, it is common for one forest age class to exhibit different structural features due to the soil 


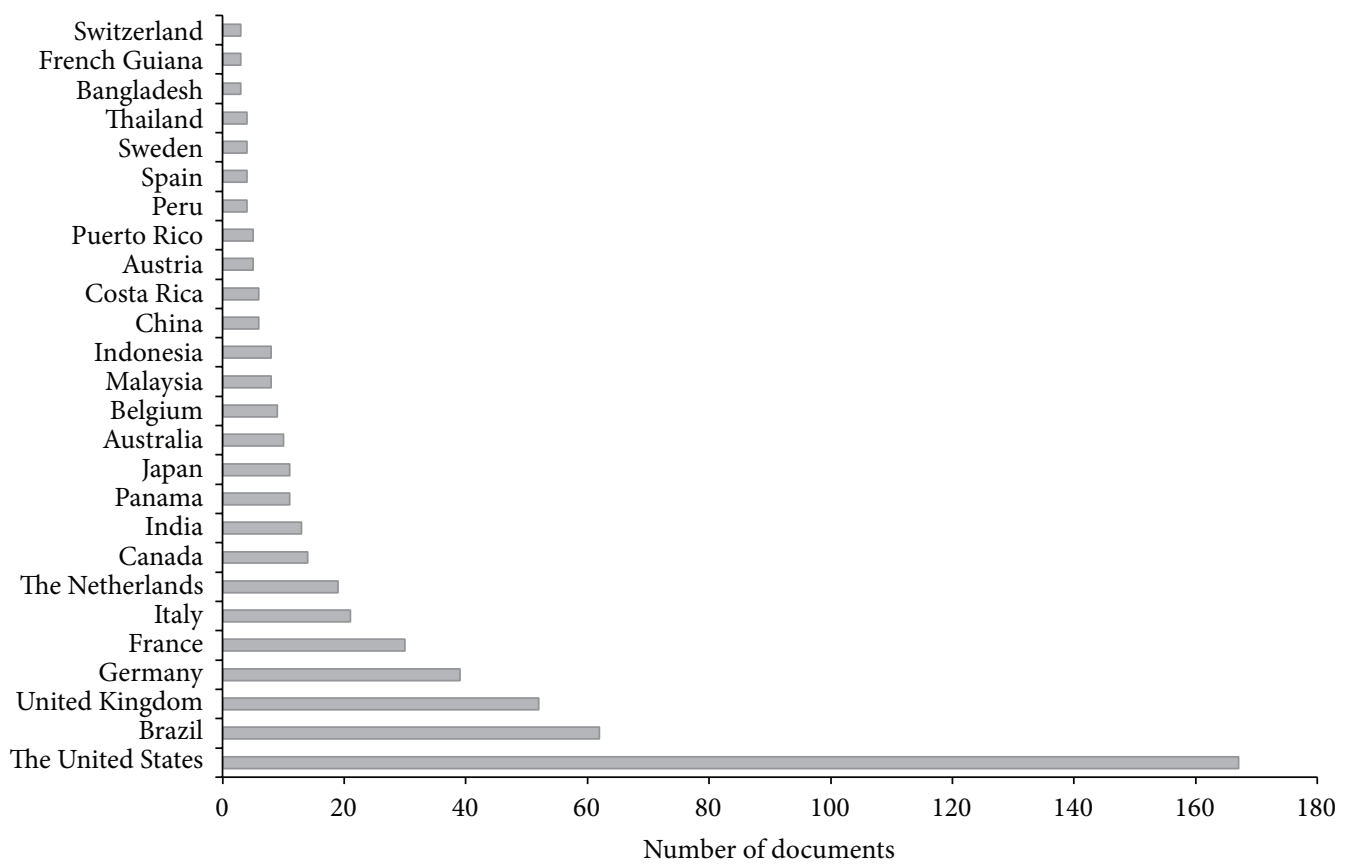

FIGURE 2: Number of articles published by author's countries. The countries included in the figure have more than two publications, considering our search criteria.

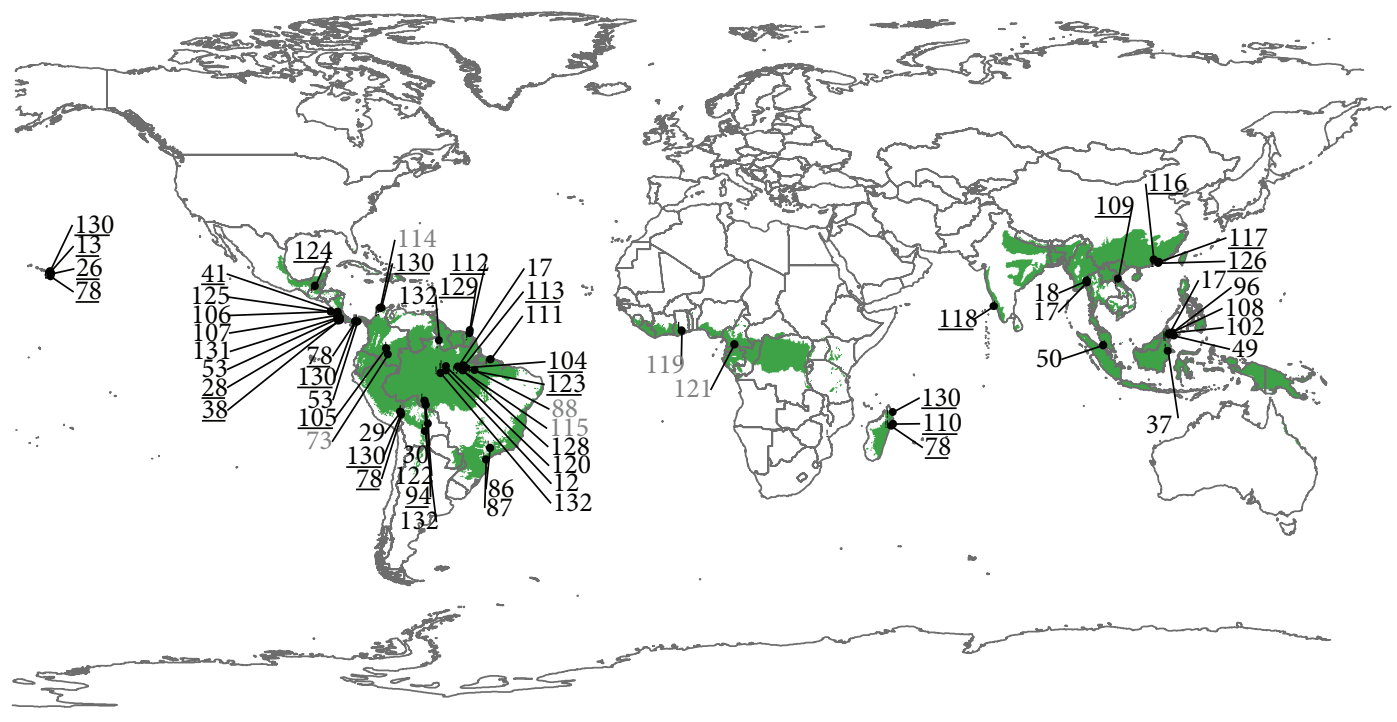

FIGURE 3: Geographic location of the selected studies. Green area refers to the distribution of the tropical forest biome. Number refers to the article identification on the references (underline black number $=$ spatial resolution $\leq 10 \mathrm{~m}$; black numbers $=$ spatial resolution $>10 \mathrm{~m}$ and $\leq 30 \mathrm{~m}$; grey numbers $=$ spatial resolution $>30 \mathrm{~m}$ ).

and geographic features or land-use history [11]. In addition, forest age or successional stand information is not always available for some forest areas [45].

\subsection{Natural and Anthropogenic Disturbance Impacts on Forest} $A G B$. Changes in the natural course of forest succession may occur due to a large number of disturbances, including wild and intentional fires, selective logging, climate change, and/or the introduction of invasive species. Forest responses to natural disturbances (i.e., storms and fire) are also a feasible use of the estimated AGB data [48]. These disturbance factors may reshape the biophysical structure of the forest or reorder the plant community, resulting in AGB dissimilarity among forest patches with different historical human intervention. Some of the reviewed studies evaluated spatial and temporal changes of tree biomass in logged forests under different management techniques. Tangki and Chappell [49] demonstrated that high-lead harvesting techniques resulted in smaller remaining tree biomasses than logging using tractor skidders. 


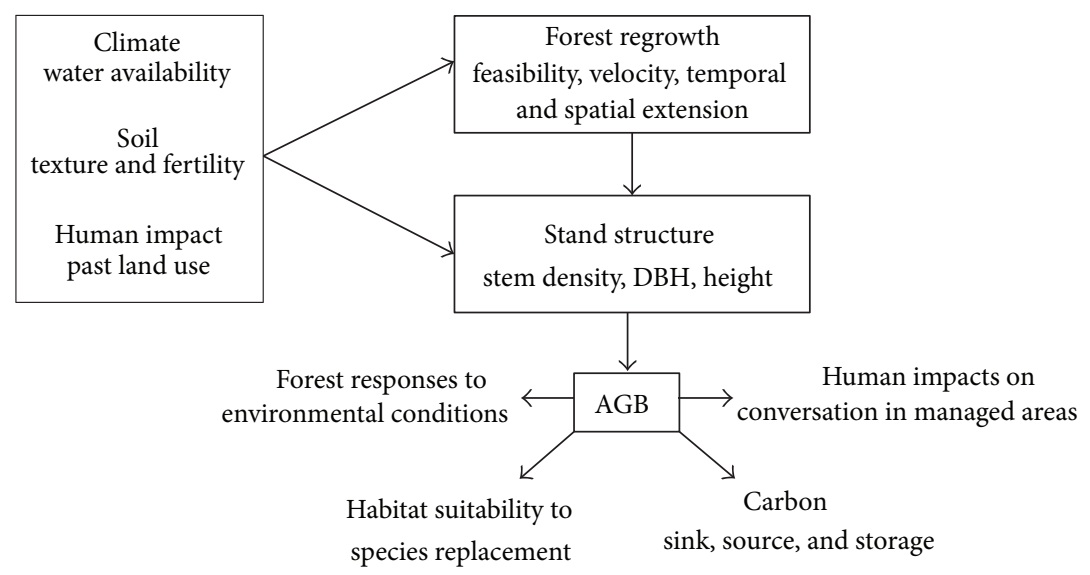

FIGURE 4: Climate, soil, and human activities determine the forest stand structure and the forest regrowth pattern. The estimated aboveground biomass (AGB) may be used as a variable to answer ecological issues, such as forest responses to environmental conditions, habitat suitability, carbon storage, and conservation in managed areas (adapted from Sarker et al. [132]).

The authors explained that the AGB differences are related to the higher levels of collateral damage caused during high-lead harvesting. In other cases, logged areas exhibited lower mean maximum crown size diameters than old-growth forests [28]. Aerial photographs revealed that tree height/diameter allometric relationships exhibit regression slope differences between logged and old-growth forests [50].

The impacts of tree species invasion on forest structures and AGB are also well studied and particularly in Hawaii, USA. Invasive tree species can rapidly spread through seeds or vegetative propagation and show opportunistic behaviours [51]. This is expected to lead to changes in overall forest AGBs. Asner et al. [26] used airborne LiDAR data to quantify forest structure and found that invasion by the tree Morella faya altered the three-dimensional structure of the rainforests, including the mean tree height, but not the total amount of AGB at the landscape level. The proliferation of tree species, Psidium cattleianum and Ficus rubiginosa, however, corresponded to decreases of $19-38 \%$ in tropical forest AGB [13].

\subsection{Forest Responses to Environmental Conditions. Environ-} mental conditions and resource availability can also affect primary net production [52] and, consequently, AGB changes throughout forest succession. Differences in the spatial and temporal distributions of precipitation across bioclimatic zones constrain forest $\mathrm{AGB}$ in some locations and were found to be an important ecological issue discussed in the reviewed literature. The increase in the number of dry months produced a reduction in forest AGB, showing the influence of net water deficits in the forest structure at regional [53] to continental scales [12]. In a study by Asner et al. [13], using airborne LiDAR data, biomass declined $53-84 \%$ in areas with increasing elevation, due to changes in temperature and humidity. On the contrary, Alves et al. [54] found AGB increment with elevation increase in the Brazilian Atlantic coast. All these examples demonstrate how environmental conditions can modulate spatial and temporal patterns of forest AGB.
Another common theme in the literature focuses on spatial distribution of biomass as related to differences among forest types. Biomes or vegetation physiognomies are closely related to environmental and climatic conditions. Wang and Qi [18] reported RS AGB differences between dry dipterocarp forests, mixed deciduous forests, and tropical evergreen forests. These results illustrate the potential use of RS AGB data to distinguish between vegetation types. However, Saatchi et al. [12] found that RS AGB data from Amazon forest was not a useful tool for distinguishing between vegetation types due to the low correlation between forest biomass and vegetation types in this biome. Asner et al. [55] integrated airborne LiDAR with maps of ecosystem types and found significant differences related to forest types and geologic substrate, allowing them to scale up the detailed LiDAR measurements to a large portion of the Southern Peruvian Amazon. Vieira et al. [11] and Saatchi et al. [12], however, found that AGB variations in tropical forests were more due to differences in soil type and land-use history than forest types. Thereby, the relationship between estimated AGB and forest succession patterns needs to be interpreted considering specific characteristics of forest types and the influence of environmental conditions among different scales of analyses.

3.4. Carbon Source, Sink, and Storage. The spatial and temporal change of AGB during the forest succession is controlled by a conjunct of environmental, biological, and human factors, as seen until now. The observed forest AGB can be directly related to tree carbon storage. Dry biomass is expected to contain approximately $50 \%$ carbon $[8,56]$. The relationship between AGB and carbon opens up a wide range of integrated discussions of the use of forest biomass for carbon monitoring $[57,58]$. Brazil, the Democratic Republic of Congo, and Indonesia have the highest carbon stocks and the largest tropical forest areas, indicating that great effort should be expended in the further verification and monitoring of data in these countries $[59,60]$.

The effect of the increase in atmospheric carbon concentration on climate change is the flagship topic for the study 


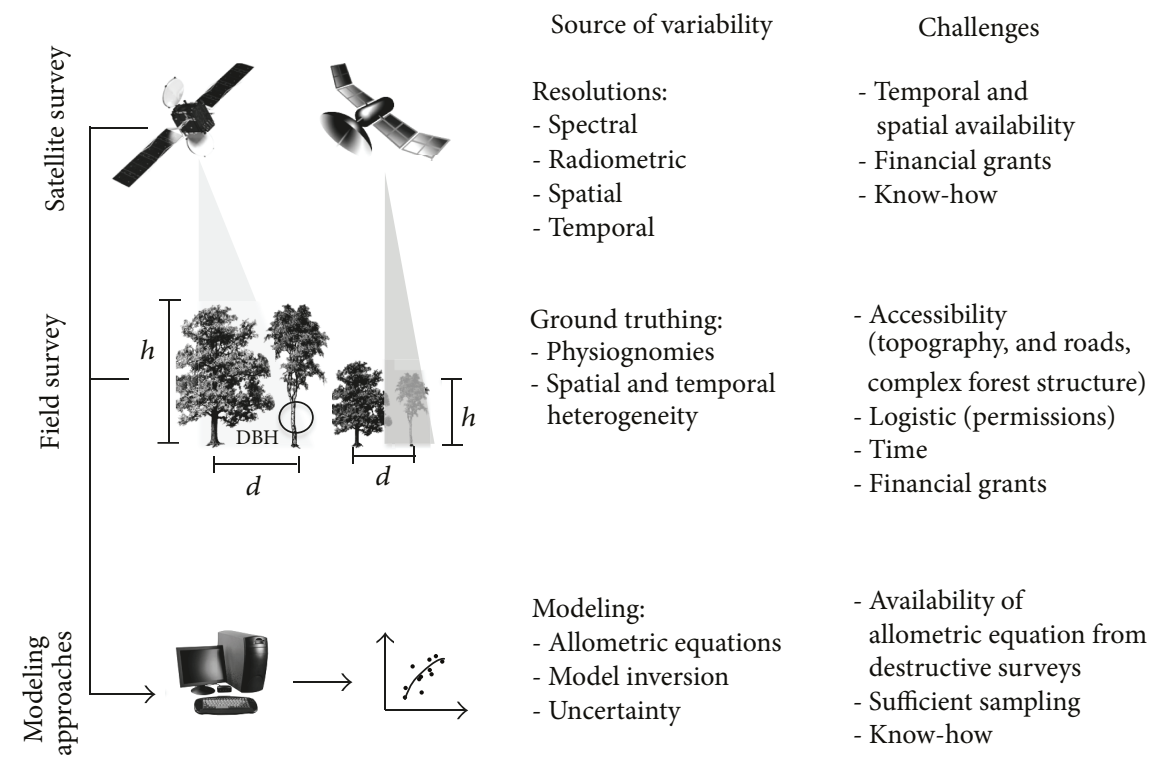

FIGURE 5: Source of variability and challenges related to each stage of aboveground biomass estimation and modelling.

and implementation of environmental carbon sinks as a result of the forest succession. The concept of carbon sinks has been criticized because of estimation biases and the difficulties associated with their quantification and verification using the available technology [61]. The difficulty in measuring changes in biomass and the lack of spatially explicit data are the main cause of variation among carbon estimates at the same area [44]. To overcome these limitations, Hall et al. [19] proposed a new orbital mission capable of estimating forest carbon storage around the world (see Section 4.1.1 for details).

3.5. Habitat Suitability. Forest structural complexity can affect animal species distributions and abundance patterns [62]. Structural attributes and microclimatic conditions change during the forest regrowth process, which can determine habitat suitability for some species [35]. A good relation of habitat heterogeneity and species diversity depends on the taxonomic group under study, how the animal guild studied perceives the vegetation structure, and the spatial resolution of the observation [63]. Biophysical forest characteristics obtained through RS data can generate continuum models related to ecological gradients and can be used to produce habitat suitability models [64].

Gradual changes in RS AGB and forest structure through space and time assessed by optical, radar, or LiDAR data have also been used to investigate the relationship between habitat heterogeneity and species diversity. Kalacska et al. [15] obtained a suitable RS model to estimate Shannon index in a tropical forest. However, the authors noted that remotely sensed data focusing on the canopy surface (i.e., surface reflection measured by Hyperion) might be inappropriate for assessing relationships between subcanopy elements, such as understory species richness. Even though the relationship between species diversity and habitat suitability has been widely documented in field-based research, the empirical knowledge of this relation may be seriously affected by the lack of information over a broad range of environmental conditions [63]. Such problems demonstrate the necessity of large-scale studies related to habitat suitability and the need to understand how RS data interact with field-based variables.

\section{Biophysical Measurement and Modeling}

Successful estimation and modeling of AGB over large scales require (a) correct selection and application of remote sensing, (b) being coupled with field data for calibration and validation, and being integrated into (c) an appropriate modeling approach (Figure 5). In this review, we focus on the information required to determine forest successional processes and spatial distribution.

\subsection{Data Sources}

4.1.1. Remote Sensing. Selection of an appropriate source of data requires first the identification of the ecological question being asked and identification of the limitations and advantages of each sensor. Overall, the combination or fusion of optical and radar data has the potential to achieve the highest accuracies in the estimated AGB $[65,66]$. Optical data can be used to improve the accuracy of radar data [12], for example, by removing leaf backscatter and compensating leaf attenuation to woody structures in each pixel [18]. Radar data (e.g., JERS-1 images) may be especially helpful as the microwaves are independent of cloud cover, a frequent problem in tropical forests. Although the trunk and branch biomass estimations coming from radar are better than the optical data estimations, the response cannot be always the same in terrains with steeper slopes [20].

Other data sources used in the studies evaluated include the Hyperion satellite sensor and aircraft based HYDICE sensor, with high spectral (220 and 210 narrow bands, resp.) and radiometric resolutions. Whereas Landsat has 8-bit 
TABLE 2: Remote sensing data used in the studies reviewed.

\begin{tabular}{|c|c|c|c|c|}
\hline Sensor & Data used & Spatial resolution & Cost & Number of case studies \\
\hline $\begin{array}{l}\text { LANDSAT/MSS, TM, and } \\
\text { ETM+ }\end{array}$ & 6 optical bands & $30 \mathrm{~m}$ & Low & 12 \\
\hline USGS/LIDAR & Airborne laser altimeter & $1.2-25 \mathrm{~m}$ & Very high & 8 \\
\hline AIRSAR $^{*}$ & Radar X, C, L, and P band & $1.5-10 \mathrm{~m}$ & High & 5 \\
\hline SAR/JERS-1 & 7 optical bands and radar L band & 18 to $24 \mathrm{~m}$ & Low & 5 \\
\hline ALOS Palsar/AVNIR-2 & Radar L band and 4 optical bands & $4.8 \mathrm{~m}$ to $9.6 \mathrm{~m}$ & Medium & 4 \\
\hline IKONOS/IKONOS & 4 optical bands & $4 \mathrm{~m}$ & High & 4 \\
\hline SPOT-5/HRS & 5 optical bands & 2.5 to $5 \mathrm{~m}$ & High & 3 \\
\hline Terra/MODIS & 7 optical bands & 250 to $500 \mathrm{~m}$ & Low & 2 \\
\hline NOAA/AVHRR & 5 optical bands & $1.1 \mathrm{Km}$ & Low & 2 \\
\hline SIR-C & $\mathrm{X}, \mathrm{C}$, and $\mathrm{L}$ bands & 15 to $25 \mathrm{~m}$ & Medium & 2 \\
\hline GLAS/ICEsat & Laser altimeter satellite & 0.75 to $75 \mathrm{~m}$ & High & 1 \\
\hline Quickbird/Quickbird & 4 optical bands & $2.4 \mathrm{~m}$ & High & 1 \\
\hline EO-1/Hyperion & 220 optical bands & $30 \mathrm{~m}$ & Very high & 1 \\
\hline NASA/QuikSCAT & Radar L and P bands & $12 \mathrm{~m}$ & Medium & 1 \\
\hline Aerial photographs & RGB true color composite & - & High & 1 \\
\hline CHRIS/PROBA & 62 optical bands & $18 \mathrm{~m}$ & Medium & 1 \\
\hline VHR Google & RGB true color composite & $1 \mathrm{~m}$ & Low & 1 \\
\hline HYDICE $^{* *}$ & 210 optical bands & 0.75 to $3.75 \mathrm{~m}$ & Very high & 1 \\
\hline ERS-1 & Radar X band & 25 & Medium & 1 \\
\hline TropiSAR & Radar L and P bands & 1.2 & Very high & 1 \\
\hline
\end{tabular}

* AIRSAR: airborne synthetic-aperture radar.

${ }^{* *}$ HYDICE: hyperspectral digital imagery collection experiment.

resolution with 256 information levels, Hyperion data has 16 bits with 65,536 information levels ranging from data range $\sim 0.4$ to $2.5 \mu \mathrm{m}$ [67]. The greater spectral resolution provided by Hyperion can result in improved sensor capabilities allowing measurements of smaller variations in reflected energy $[68,69]$, which can be related to forest biomass or phytochemical characteristics of the canopy. The capacity of hyperspectral sensors to differentiate tree phytochemical features enables more detailed estimates of forest structural data in the forest succession studies, partly related to improved mapping of canopy chemistry related to the tree species composition. Some research initiatives have achieved successful measurements of forest structure and species composition by merging LiDAR (tree height) and hyperspectral (phytochemical) data $[70,71]$, which is an important ongoing focus for studies on the direction and rate of the forest succession.

LiDAR systems can be used to obtain both top of canopy and within canopy structural information as some systems can have effective signal penetration through the forest canopy, resulting in 3D vegetation structure data $[53,72]$ with spatial resolution varying according to the system design and flight altitude above the study area. LiDAR is now considered to be the state of the art for remote sensing based biomass estimation but has significant disadvantages related to the high cost per area, lack of historical data for temporal analysis, and the unavailability of large-scale datasets making regional or global AGB estimation with airborne LiDAR unfeasible $[59,73]$. To mitigate this problem, there is a need for a satellite based platform providing global LiDAR data optimized for AGB estimation with errors less than 10 to $25 \mathrm{MgC} \mathrm{ha}^{-1}$ [19].
The sensors used in the reviewed studies mainly differed in cost and temporal, spatial, spectral, and radiometric resolutions (Table 2). The widespread use of Landsat TM data may be attributed to the low cost of this data. Despite this, the main limitation of the Landsat images is the reflectance saturation at higher biomass values [20]. However, the longer time span of available information (since 1984) is an advantage of Landsat data that can play an important role in temporal forest regrowth analyses.

Multitemporal imagery can be an important source of data for the study of forest regrowth patterns, but the data processing should account for atmospheric corrections and phenological effects. Atmospheric conditions can influence optical RS data through two processes: the absorption and the scatter of solar radiance [74]. The main problem is that images from different dates were acquired under different atmospheric conditions, and preprocessing analyses need to accurately correct for these differences [75]. The comparison of multiple images from different months to monitor successional changes also needs to consider signal effect resulting from phenological variations in the canopy. Seasonal changes in solar zenith angle, variations in the amount of leaves in the canopy, and the growth of understory vegetation are the main features that can confound remotely sensed signals [76].

4.1.2. Ground Truthing. The reviewed studies obtained ground truthing field data from plots or through the point quadrant method. The total sampled area ranged from 1.5 to $272 \mathrm{ha}$, but in $70 \%$ of the studies the area ranged from 1 ha to 9.5 ha. Access difficulties may create restrictions to 
the sampling of larger areas. Studies with small sampling areas tended to overestimate AGB per hectare, but this tendency is not always significant [77]. Even so, ground truthing of only small areas may result in site-specific models and limit the transferability of the model to other areas [17]. To minimize this condition some studies have used large field databases merging data from different regions $[12,73,78]$.

The suitability of the method depends on the scale of the study area and the structural heterogeneity of the forest $[79,80]$. The greater the sampling spatial scale, the greater the probability of having good representation of forest structural heterogeneity in the region, indicating that a broad sample area may be required. Moreover, there is a need for a minimum knowledge about the spatial distribution of the forest structure studied [81] and the local influence of the topography and soil on the AGB. Tropical trees tend to exhibit an aggregation pattern [82] and high variability within short spatial distances in forest structure and biomass [83], resulting in a complex mosaic that can be difficult to fully sample. The use of plots greater than 0.1 ha has been shown to be more reliable than smaller plots, which is also related to decreased stochastic small-scale disturbances having disproportionate weighting on total measured structure and AGB [83], maintain greater spatial overlap between ground-reference and sensor data, capture greater forest variability, and reduce edge noise from neighbouring trees [84]. The use of the point quadrant method has the advantage of evaluating forest heterogeneity at less effort and lower cost than plot-based sampling, but this method can underestimate densities and basal areas [85]. The studies that used point quadrant methods also showed high correlation values between field and RS data $[18,86]$. Nevertheless, the use of this method needs to be better evaluated as a ground truthing option because such a method has the potential to be used in large-scale studies with reduced fieldwork [87]. Furthermore, a hierarchical sampling scheme of plots, quadrants, and subquadrants can be a good way to include this complexity [88]. Data from the smallest scale (subquadrant) can be treated as random draws from an unobserved quadrant and modeled to obtain uncertainty parameters for the regression of quadrant and satellite data [89].

\subsection{Statistical Modeling}

4.2.1. Allometric Equations to Estimate Forest Biomass. The studies reviewed used between 1 and 16 different allometric equations per study to estimate AGB. Different allometric relations between biomass and tree diameter or height are set by environmental (e.g., ground slope, climatic conditions, and light level) or biological factors [90] and can explain up to $90-95 \%$ of the ground AGB $[11,91]$. Testing allometric model accuracies, Vieira et al. [92] applied several allometric equations (developed by different authors) to the same diameter at breast height $(\mathrm{DBH})$ and height and found a difference of $5-7 \%$ in AGB estimations, indicating a source of error dependent upon the equation choice. Another source of error in the forest AGB estimation may be the lack of information from nonarboreal sources (such as lianas, palms, tree ferns, bamboo, and epiphytes), which can account for more than $10 \%$ of the AGB in Atlantic Forest areas [92].

The choice of the equation used to estimate AGB may depend on the height and $\mathrm{DBH}$ range and on the species composition of the forest studied. Attention to these factors may improve the suitability of the biomass estimation using allometric equations [88, 93]. Another option would be to include wood density in the biomass estimation, providing a more accurate representation of tree biomass than those relying only on DBH and height [94]. When species-level data are not available, a mean wood density by forest type, family, or genus can be used [53].

\subsubsection{Remotely Sensed Biomass Estimation by Model Inver-} sion. The main statistical tool used in the studies to relate field and RS data was parametric statistic ( $90 \%$ of the studies). This statistic approach uses continuous biomass data as dependent variable and RS data as independent variable. Modeled biomass values from tropical forests can display nonlinear trends in the residuals, indicating the use of nonlinear models [45]. Li et al. [88] obtained better adjusted $R$ squared and mean squared error values using nonlinear models than linear models and presented a clear framework to develop a nonlinear biomass model for tropical forests. However, about $50 \%$ of the studies used linear regression (simple or multiple). Therefore, the choice between linear or nonlinear approaches depends on their statistical requirements. In both cases, linear or nonlinear equations, the resulted equations are frequently used to predict biomass data in areas not surveyed with field work. Generalized linear models (GLM) have also been used to analyze the suitability of AGB models using Akaike Information Criterion and $R$-squared values to evaluate model performances $[87,95]$. GLM models allow us to explore combinations of factors, covariates, and interactions among variables through a process called iteratively reweighted least squares. This overcomes the basic problem related to regression models that is the change in the variance as a consequence of the transformation of the data to attain normality [96].

Finally, other predictive models used in the reviewed studies were decision tree and neural networks. Decision trees use hierarchical set of rules to define classes and it does not assume any a priori statistical characteristics for the input data layers [12]. The use of neural networks is an alternative that can play a significant role in obtaining better accuracy [97]. However, neural network models have a substantial subjective component and can be relatively poor for semantically related field and remotely sensed data [98].

4.3. Uncertainty. In the modeling context, uncertainty is the lack of knowledge of the true values of a variable, which can be estimated by the range and likelihood of possible values [57]. The overall uncertainty in AGB estimation using RS is directly related to the relationship between a set of potential errors coming from processing satellite data (Section 4.1.1), field data (Section 4.1.2), statistical modeling (Section 4.2), and the ecological variables studied. Beyond the uncertainty from each variable, the errors can come from the interaction 
among them, for example, in the conflict of scale between satellite and field data samples. The challenge is to balance how the errors influence the ecological data interpretation and how the errors from each modeling step influence the overall error.

Most studies considered were mainly performed in flat forest areas. In optical images, ground slope can shade areas, resulting in decreased reflectance values compared to flat areas [99] and the generation of spectral differences between forests at the same successional stage [76]. These topographic effects can be minimized by different algorithmic corrections [100], but biases may still be included in analyses [87].

The position errors of the sensor data can also reduce the modeling accuracy in pixel-based modeling [76]. Two common strategies were used to minimize this problem: the correlation of the field data with a $3 \times 3$ or $5 \times 5$ pixel window around the ground data $[15,98,101]$ and the use of a mean radiance from a forest patch $[18,49]$. These approaches can also reduce the confidence level of the model due to the high area disproportion between the field area plot (i.e., 0.09 ha) and the pixel window from, for example, the Landsat data ( 2.25 ha in a $5 \times 5$ window).

The root mean square error (RMSE) and determination coefficient values were widely used to compare the accuracies of the AGB estimates. The error estimate had a mean value of 41.2 $\mathrm{Mg} \mathrm{ha}^{-1}\left(\mathrm{SD}=29.3 \mathrm{Mg} \mathrm{ha}^{-1}\right)$, considering the reviewed studies that present this analysis in the results (17 studies from the 46 analyzed). Commonly, the RMSE is obtained from the comparison of model predictions with independent data. Data can be randomly separated in two groups, one to implement the model and one to check its performance. This process can be repeated many times to obtain randomized RMSE values. Finally, all values are used to build up the overall error probability density function, which can be used to evaluate the magnitude and trend direction of the errors [57].

Li et al. [88] found that the AGB model might show inflated residual variances toward higher biomass values. The authors noted that this can be associated with the application of the same allometric equation to trees with different sizes and forest with different structure complexities. Errors in forest AGB estimation can be random or systematic [83]. Minor AGB errors have been found in forests with low biomass $[12,53,102]$.

Despite these inherent modeling errors, biomass estimation using exclusively field data is far from being easy and is free of errors [17]. Studies based only on field information are accurate at the local scale but may fail to take into account the large spatial variability of biomass. AGB estimations using only field data over large areas showed an overall sampling error of approximately $\pm 20 \%[54,103]$. Moreover, field-based measurements and estimates are time consuming, labor intensive, and difficult to implement in remote areas [20]. Challenges exist in the collection of both RS and field data. However, the integration of these different sources of information is crucial to better AGB estimates in any sites.

\section{Synthesis and Future Research}

In this review we highlight the advantages and disadvantages of estimating forest biomass from remote sensing. Remote sensing of aboveground biomass is critical to understand forest succession and landscape dynamics. Forest biomass relates to unique regrowth patterns, including rates and directions, which are partly determined by natural and anthropogenic disturbances. As species composition changes occur simultaneously to changes in forest structure and related aboveground biomass, study approaches limited to forest structure may have high errors in correctly identifying forest successional stages. This problem may be alleviated through fusion of sensors capable of deriving detailed structural (e.g., radar and LiDAR) and phytochemical (e.g., hyperspectral images) features of the forest canopy.

Access to historical ground truthing information remains one of the main difficulties in multitemporal comparisons of AGB. Most of the selected studies indicated forest regrowth as a potential subject to be analyzed by AGB estimation but do not address the topic. Further interpretation of tropical forest ecological processes, as can be derived from remotely sensed forest structure, is required [13]. Nevertheless, the potential for the use of remotely sensed biomass estimations in forest succession studies in tropical forests remains high. More detailed analyses on the spatial distribution of AGB are merited for improved forest management, conservation status evaluation, carbon source and sink investigations, and better understanding implications of environmental conditions, including climatic change, on forest structure and composition.

Our review indicates that accuracy and precision assessment are the most important challenges related. The uncertainty estimates need to be robust and transparent, due to the current importance for decision makers [58]. In addition, the evaluation of the studies reviewed here indicates that errors in AGB estimations can in some cases be the same as annual AGB changes by regrowth process, making AGB comparisons on a short time scale unfeasible using imprecise or biased data. However, long time scale lag comparisons are still possible if attention is paid to spectral variations between satellite images related to atmospheric conditions and satellite signal degradation over time. Hall et al. [19] highlighted the importance of a new space mission with a technology able to obtain biophysical forest estimates with lower errors in short time scale comparisons.

A reliable AGB estimation depends on the sensor type, processing strategy and forest characteristics. In focusing attention only on the RS data process, we may fail to identify critical ecological patterns. Our results suggest that sampling choices depend on intrinsic forest features and sources of noise related, for example, to topographic characteristics. In addition, we discussed some positive and negative features of each sensor for obtaining AGB estimations. The choice of data source depends on trade-offs between advantages and disadvantages of methodological and technological features.

When making a modeling choice, attention must be paid to potential sources of bias in the biomass regression models, including (a) sample size, (b) accuracy of the allometric equations, (c) image calibration, (d) the methodology used for temporal adjustments between the sampled biomass data and satellite observations, (e) the multicollinearity of the polynomial model [88], (f) the fact that $30-50 \%$ of the forest 
biomass is hidden by emergent trees [94], (g) the increased number of lianas in the intermediate successional stage [15], (h) topography, and (i) the past land-use context in the study of forest regrowth dynamics.

\section{Conflict of Interests}

The authors declare that there is no conflict of interests regarding the publication of this paper.

\section{Acknowledgments}

The authors express their gratitude to E. Sebastián González, Paulo I. de Knegt Lopez de Prado, G. Kuntschik, J. A. Quintanilha, and L. R. Tambosi for commenting on earlier versions of this paper.

\section{References}

[1] F. Achard, H. D. Eva, H.-J. Stibig et al., "Determination of deforestation rates of the world's humid tropical forests," Science, vol. 297, no. 5583, pp. 999-1002, 2002.

[2] A. Grainger, "Difficulties in tracking the long-term global trend in tropical forest area," Proceedings of the National Academy of Sciences of the United States of America, vol. 105, no. 2, pp. 818823, 2008.

[3] G. P. Asner, T. K. Rudel, T. M. Aide, R. Defries, and R. Emerson, "A contemporary assessment of change in humid tropical forests," Conservation Biology, vol. 23, no. 6, pp. 1386-1395, 2009.

[4] J. Blaser, A. Sarre, D. Poore, and S. Johnson, Status of Tropical Forest Management, Technical Series No. 38, International Tropical Timber Organization, Yokohama, Japan, 2011, Edited by ITTO.

[5] S. J. Wright, "Tropical forests in a changing environment," Trends in Ecology \& Evolution, vol. 20, no. 10, pp. 553-560, 2005.

[6] R. L. Chazdon, C. A. Peres, D. Dent et al., "The potential for species conservation in tropical secondary forests," Conservation Biology, vol. 23, no. 6, pp. 1406-1417, 2009.

[7] D. H. Dent and S. J. Wright, "The future of tropical species in secondary forests: a quantitative review," Biological Conservation, vol. 142, no. 12, pp. 2833-2843, 2009.

[8] A. R. Martin and S. C. Thomas, "A reassessment of carbon content in tropical trees," PLoS ONE, vol. 6, no. 8, Article ID e23533, 2011.

[9] A. E. Lugo, “The emerging era of novel tropical forests," Biotropica, vol. 41, no. 5, pp. 589-591, 2009.

[10] S. Brown and A. E. Lugo, “Tropical secondary forests," Journal of Tropical Ecology, vol. 6, no. 1, pp. 1-32, 1990.

[11] I. C. G. Vieira, A. S. de Almeida, E. A. Davidson, T. A. Stone, C. J. Reis de Carvalho, and J. B. Guerrero, "Classifying successional forests using Landsat spectral properties and ecological characteristics in eastern Amazônia," Remote Sensing of Environment, vol. 87, no. 4, pp. 470-481, 2003.

[12] S. S. Saatchi, R. A. Houghton, R. C. Dos Santos Alvalá, J. V. Soares, and Y. Yu, "Distribution of aboveground live biomass in the Amazon basin," Global Change Biology, vol. 13, no. 4, pp. 816-837, 2007.

[13] G. P. Asner, R. F. Hughes, T. A. Varga, D. E. Knapp, and T. Kennedy-Bowdoin, "Environmental and biotic controls over aboveground biomass throughout a tropical rain forest," Ecosystems, vol. 12, no. 2, pp. 261-278, 2009.

[14] J. Grace, "Understanding and managing the global carbon cycle," Journal of Ecology, vol. 92, no. 2, pp. 189-202, 2004.

[15] M. Kalacska, G. A. Sanchez-Azofeifa, B. Rivard, T. Caelli, H. P. White, and J. C. Calvo-Alvarado, "Ecological fingerprinting of ecosystem succession: estimating secondary tropical dry forest structure and diversity using imaging spectroscopy," Remote Sensing of Environment, vol. 108, no. 1, pp. 82-96, 2007.

[16] J. Q. Chambers, G. P. Asner, D. C. Morton et al., "Regional ecosystem structure and function: ecological insights from remote sensing of tropical forests," Trends in Ecology \& Evolution, vol. 22, no. 8, pp. 414-423, 2007.

[17] G. M. Foody, D. S. Boyd, and M. E. J. Cutler, "Predictive relations of tropical forest biomass from Landsat TM data and their transferability between regions," Remote Sensing of Environment, vol. 85, no. 4, pp. 463-474, 2003.

[18] C. Wang and J. Qi, "Biophysical estimation in tropical forests using JERS-1 SAR and VNIR imagery. II. Aboveground woody biomass," International Journal of Remote Sensing, vol. 29, no. 23, pp. 6827-6849, 2008.

[19] F. G. Hall, K. Bergen, J. B. Blair et al., "Characterizing 3D vegetation structure from space: mission requirements," Remote Sensing of Environment, vol. 115, no. 11, pp. 2753-2775, 2011.

[20] D. Lu, "The potential and challenge of remote sensing-based biomass estimation," International Journal of Remote Sensing, vol. 27, no. 7, pp. 1297-1328, 2006.

[21] C. Eisfelder, C. Kuenzer, and S. Dech, "Derivation of biomass information for semi-arid areas using remote-sensing data," International Journal of Remote Sensing, vol. 33, no. 9, pp. 29372984, 2012.

[22] R. L. Chazdon, S. G. Letcher, M. van Breugel, M. MartínezRamos, F. Bongers, and B. Finegan, "Rates of change in tree communities of secondary Neotropical forests following major disturbances," Philosophical Transactions of the Royal Society B: Biological Sciences, vol. 362, no. 1478, pp. 273-289, 2007.

[23] J. Groeneveld, L. F. Alves, L. C. Bernacci et al., "The impact of fragmentation and density regulation on forest succession in the Atlantic rain forest," Ecological Modelling, vol. 220, no. 19, pp. 2450-2459, 2009.

[24] B. A. Santos, C. A. Peres, M. A. Oliveira, A. Grillo, C. P. AlvesCosta, and M. Tabarelli, "Drastic erosion in functional attributes of tree assemblages in Atlantic forest fragments of northeastern Brazil," Biological Conservation, vol. 141, no. 1, pp. 249260, 2008.

[25] M. Tabarelli, A. V. Lopes, and C. A. Peres, "Edge-effects drive tropical forest fragments towards an early-successional system," Biotropica, vol. 40, no. 6, pp. 657-661, 2008.

[26] G. P. Asner, R. E. Martin, D. E. Knapp, and T. KennedyBowdoin, "Effects of Morella faya tree invasion on aboveground carbon storage in Hawaii," Biological Invasions, vol. 12, no. 3, pp. 477-494, 2010.

[27] C. Uhl, R. Buschbacher, and E. A. S. Serrao, "Abandoned pastures in eastern Amazonia. I. Patterns of plant succession," Journal of Ecology, vol. 76, no. 3, pp. 663-681, 1988.

[28] D. B. Clark, J. M. Read, M. L. Clark, A. M. Cruz, M. F. Dotti, and D. A. Clark, "Application of 1-m and 4-m resolution satellite data to ecological studies of tropical rain forests," Ecological Applications, vol. 14, no. 1, pp. 61-74, 2004.

[29] L. Naughton-Treves, "Deforestation and carbon emissions at tropical frontiers: a case study from the Peruvian Amazon," World Development, vol. 32, no. 1, pp. 173-190, 2004. 
[30] E. H. Helmer, M. A. Lefsky, and D. A. Roberts, "Biomass accumulation rates of Amazonian secondary forest and biomass of old-growth forests from Landsat time series and the Geoscience Laser Altimeter System," Journal of Applied Remote Sensing, vol. 3, no. 1, Article ID 033505, pp. 1-31, 2009.

[31] S. G. Rolim, R. M. Jesus, H. E. M. Nascimento, H. T. Z. do Couto, and J. Q. Chambers, "Biomass change in an Atlantic tropical moist forest: the ENSO effect in permanent sample plots over a 22-year period," Oecologia, vol. 142, no. 2, pp. 238-246, 2005.

[32] M. E. Swanson, J. F. Franklin, R. L. Beschta et al., "The forgotten stage of forest succession: early-successional ecosystems on forest sites," Frontiers in Ecology and the Environment, vol. 9, no. 2, pp. 117-125, 2011.

[33] M. R. Guariguata and R. Ostertag, "Neotropical secondary forest succession: changes in structural and functional characteristics," Forest Ecology and Management, vol. 148, no. 1-3, pp. 185206, 2001.

[34] D. Liebsch, M. C. M. Marques, and R. Goldenberg, "How long does the Atlantic Rain Forest take to recover after a disturbance? Changes in species composition and ecological features during secondary succession," Biological Conservation, vol. 141, no. 6, pp. 1717-1725, 2008.

[35] M. E. Bowen, C. A. McAlpine, A. P. N. House, and G. C. Smith, "Regrowth forests on abandoned agricultural land: a review of their habitat values for recovering forest fauna," Biological Conservation, vol. 140, no. 3-4, pp. 273-296, 2007.

[36] A. M. A. Zambrano, E. N. Broadbent, M. Schmink, S. G. Perz, and G. P. Asner, "Deforestation drivers in Southwest Amazonia: comparing smallholder farmers in Iñapari, Peru, and Assis Brasil, Brazil," Conservation \& Society, vol. 8, no. 3, pp. 157-170, 2010.

[37] A. Wijaya, V. Liesenberg, and R. Gloaguen, "Retrieval of forest attributes in complex successional forests of Central Indonesia: modeling and estimation of bitemporal data," Forest Ecology and Management, vol. 259, no. 12, pp. 2315-2326, 2010.

[38] J. R. Kellner, D. B. Clark, and S. P. Hubbell, "Pervasive canopy dynamics produce short-term stability in a tropical rain forest landscape," Ecology Letters, vol. 12, no. 2, pp. 155-164, 2009.

[39] A. T. Hudak, E. K. Strand, L. A. Vierling et al., "Quantifying aboveground forest carbon pools and fluxes from repeat LiDAR surveys," Remote Sensing of Environment, vol. 123, pp. 25-40, 2012.

[40] C. M. Ryan, T. Hill, E. Woollen et al., "Quantifying smallscale deforestation and forest degradation in African woodlands using radar imagery," Global Change Biology, vol. 18, no. 1, pp. 243-257, 2012.

[41] A. S. Antonarakis, S. S. Saatchi, R. L. Chazdon, and P. R. Moorcroft, "Using LiDAR and Radar measurements to constrain predictions of forest ecosystem structure and function," Ecological Applications, vol. 21, no. 4, pp. 1120-1137, 2011.

[42] S. R. Baptista and T. K. Rudel, "A re-emerging Atlantic forest? Urbanization, industrialization and the forest transition in Santa Catarina, southern Brazil," Environmental Conservation, vol. 33, no. 3, pp. 195-202, 2006.

[43] S. R. Baptista, "Metropolization and forest recovery in southern Brazil: a multiscale analysis of the Florianópolis city-region, Santa Catarina state, 1970 to 2005," Ecology and Society, vol. 13, no. 2, article 5, 2008.

[44] R. A. Houghton, "Aboveground forest biomass and the global carbon balance," Global Change Biology, vol. 11, no. 6, pp. 945958, 2005.
[45] W. Liu, C. Song, T. A. Schroeder, and W. B. Cohen, "Predicting forest successional stages using multitemporal Landsat imagery with forest inventory and analysis data," International Journal of Remote Sensing, vol. 29, no. 13, pp. 3855-3872, 2008.

[46] T. Neeff, R. M. Lucas, J. R. D. Santos, E. S. Brondizio, and C. C. Freitas, "Area and age of secondary forests in Brazilian Amazonia 1978-2002: an empirical estimate," Ecosystems, vol. 9, no. 4, pp. 609-623, 2006.

[47] A. H. Sirén and E. S. Brondizio, "Detecting subtle land use change in tropical forests," Applied Geography, vol. 29, no. 2, pp. 201-211, 2009.

[48] K. A. Dolan, G. C. Hurtt, J. Q. Chambers, R. O. Dubayah, S. Frolking, and J. G. Masek, "Using ICESat's Geoscience Laser Altimeter System (GLAS) to assess large-scale forest disturbance caused by hurricane Katrina," Remote Sensing of Environment, vol. 115, no. 1, pp. 86-96, 2011.

[49] H. Tangki and N. A. Chappell, "Biomass variation across selectively logged forest within a $225-\mathrm{km}^{2}$ region of Borneo and its prediction by Landsat TM," Forest Ecology and Management, vol. 256, no. 11, pp. 1960-1970, 2008.

[50] T. Okuda, M. Suzuki, S. Numata et al., "Estimation of aboveground biomass in logged and primary lowland rainforests using 3-D photogrammetric analysis," Forest Ecology and Management, vol. 203, no. 1-3, pp. 63-75, 2004.

[51] P. E. Busby, P. Vitousek, and R. Dirzo, "Prevalence of tree regeneration by sprouting and seeding along a rainfall gradient in Hawai'i," Biotropica, vol. 42, no. 1, pp. 80-86, 2010.

[52] D. A. Clark, S. Brown, D. W. Kicklighter et al., "Net primary production in tropical forests: an evaluation and synthesis of existing field data," Ecological Applications, vol. 11, no. 2, pp. 371$384,2001$.

[53] J. B. Drake, R. G. Knox, R. O. Dubayah et al., "Aboveground biomass estimation in closed canopy Neotropical forests using lidar remote sensing: factors affecting the generality of relationships," Global Ecology \& Biogeography, vol. 12, no. 2, pp. 147-159, 2003.

[54] L. F. Alves, S. A. Vieira, M. A. Scaranello et al., "Forest structure and live aboveground biomass variation along an elevational gradient of tropical Atlantic moist forest (Brazil)," Forest Ecology and Management, vol. 260, no. 5, pp. 679-691, 2010.

[55] G. P. Asner, G. V. N. Powell, J. Mascaro et al., "High-resolution forest carbon stocks and emissions in the Amazon," Proceedings of the National Academy of Sciences of the United States of America, vol. 107, no. 38, pp. 16738-16742, 2010.

[56] S. Brown and A. E. Lugo, "The storage and production of organic matter in tropical forests and their role in the global carbon cycle," Biotropica, vol. 14, no. 3, pp. 161-187, 1982.

[57] IPCC, 2006 IPCC Guidelines for National Greenhouse Gas Inventories, National Greenhouse Gas Inventories Programme, Kanagawa, Japan, 2006, Edited by H.S. Eggleston, L. Buendia, K. Miwa, T. Ngara and K. Tanabe.

[58] IPCC, "Expert meeting on national forest GHC inventories," in National Forest GHC Inventories-A Stock Taking, H. S. Eggleston, N. Srivastava, K. Tanabe, and J. Baasansuren, Eds., IGES, Hayama, Japan, 2010.

[59] S. S. Saatchi, N. L. Harris, S. Brown et al., "Benchmark map of forest carbon stocks in tropical regions across three continents," Proceedings of the National Academy of Sciences of the United States of America, vol. 108, no. 24, pp. 9899-9904, 2011.

[60] FAO, State of the World's Forests, Food and Agriculture Organization, Rome, Italy, 2011. 
[61] B. Freedman, G. Stinson, and P. Lacoul, "Carbon credits and the conservation of natural areas," Environmental Reviews, vol. 17, pp. 1-19, 2009.

[62] M. Heindl and H. Winkler, "Vertical lek placement of forestdwelling manakin species (Aves, Pipridae) is associated with vertical gradients of ambient light," Biological Journal of the Linnean Society, vol. 80, no. 4, pp. 647-658, 2003.

[63] J. Tews, U. Brose, V. Grimm et al., "Animal species diversity driven by habitat heterogeneity/diversity: the importance of keystone structures," Journal of Biogeography, vol. 31, no. 1, pp. 79-92, 2004.

[64] J. Fischer and D. L. Lindenmayer, "Beyond fragmentation: the continuum model for fauna research and conservation in human-modified landscapes," Oikos, vol. 112, no. 2, pp. 473-480, 2006.

[65] T. M. Kuplich, "Classifying regenerating forest stages in Amazônia using remotely sensed images and a neural network," Forest Ecology and Management, vol. 234, no. 1-3, pp. 1-9, 2006.

[66] S. G. Zolkos, S. J. Goetz, and R. Dubayah, "A meta-analysis of terrestrial aboveground biomass estimation using lidar remote sensing," Remote Sensing of Environment, vol. 128, pp. 289-298, 2013.

[67] J. Pearlman, S. Carman, C. Segal, P. Jarecke, P. Clancy, and W. Browne, "Overview of the hyperion imaging spectrometer for the NASA EO-1 mission," in Proceedings of the IEEE International Geoscience and Remote Sensing Symposium (IGARSS '01), vol. 7, pp. 3036-3038, Sydney, Australia, July 2001.

[68] C. J. Legleiter, W. A. Marcus, and R. L. Lawrence, "Effects of sensor resolution on mapping in-stream habitats," Photogrammetric Engineering \& Remote Sensing, vol. 68, no. 8, pp. 801-807, 2002.

[69] P. S. Thenkabail, E. A. Enclona, M. S. Ashton, C. Legg, and M. J. de Dieu, "Hyperion, IKONOS, ALI, and ETM+ sensors in the study of African rainforests," Remote Sensing of Environment, vol. 90, no. 1, pp. 23-43, 2004.

[70] G. P. Asner, D. E. Knapp, J. Boardman et al., "Carnegie Airborne Observatory-2: increasing science data dimensionality via highfidelity multi-sensor fusion," Remote Sensing of Environment, vol. 124, pp. 454-465, 2012.

[71] J. B. Féret and G. P. Asner, "Semi-supervised methods to identify individual crowns of lowland tropical canopy species using imaging spectroscopy and LiDAR," Remote Sensing, vol. 4, no. 8, pp. 2457-2476, 2012.

[72] M. L. Imhoff, "Theoretical analysis of the effect of forest structure on synthetic aperture radar backscatter and the remote sensing of biomass," IEEE Transactions on Geoscience and Remote Sensing, vol. 33, no. 2, pp. 341-352, 1995.

[73] J. A. Anaya, E. Chuvieco, and A. Palacios-Orueta, "Aboveground biomass assessment in Colombia: a remote sensing approach," Forest Ecology and Management, vol. 257, no. 4, pp. 1237-1246, 2009.

[74] E. F. Vermote, D. Tanré, J. L. Deuzé, M. Herman, and J.-J. Morcrette, "Second simulation of the satellite signal in the solar spectrum, 6s: an overview," IEEE Transactions on Geoscience and Remote Sensing, vol. 35, no. 3, pp. 675-686, 1997.

[75] M. Latorre, O. A. C. Júnior, A. P. F. Carvalho, and Y. E. Shimabukuro, "Correção atmosférica: conceito e fundamentos," Espaço \& Geografia, vol. 5, pp. 153-178, 2002.

[76] C. Song and C. E. Woodcock, "Monitoring forest succession with multitemporal landsat images: factors of uncertainty," IEEE Transactions on Geoscience and Remote Sensing, vol. 41, no. 11, pp. 2557-2567, 2003.
[77] S. Brown and A. E. Lugo, "Aboveground biomass estimates for tropical moist forests of the Brazilian Amazon," Interciência, vol. 17, pp. 8-18, 1992.

[78] G. P. Asner, J. Mascaro, H. C. Muller-Landau et al., "A universal airborne LiDAR approach for tropical forest carbon mapping," Oecologia, vol. 168, no. 4, pp. 1147-1160, 2012.

[79] A. Luckman, J. Baker, T. M. Kuplich, F. Y. Corina da Costa, and C. F. Alejandro, "A study of the relationship between radar backscatter and regenerating tropical forest biomass for spaceborne SAR instruments," Remote Sensing of Environment, vol. 60, no. 1, pp. 1-13, 1997.

[80] R. A. Houghton, K. T. Lawrence, J. L. Hackler, and S. Brown, "The spatial distribution of forest biomass in the Brazilian Amazon: a comparison of estimates," Global Change Biology, vol. 7, no. 7, pp. 731-746, 2001.

[81] E. Tomppo, H. Olsson, G. Ståhl, M. Nilsson, O. Hagner, and M. Katila, "Combining national forest inventory field plots and remote sensing data for forest databases," Remote Sensing of Environment, vol. 112, no. 5, pp. 1982-1999, 2008.

[82] S. P. Hubbell, "Tree dispersion, abundance, and diversity in a tropical dry forest," Science, vol. 203, no. 4387, pp. 1299-1309, 1979.

[83] S. Saatchi, M. Marlier, R. L. Chazdon, D. B. Clark, and A. E. Russell, "Impact of spatial variability of tropical forest structure on radar estimation of aboveground biomass," Remote Sensing of Environment, vol. 115, no. 11, pp. 2836-2849, 2011.

[84] G. W. Frazer, S. Magnussen, M. A. Wulder, and K. O. Niemann, "Simulated impact of sample plot size and co-registration error on the accuracy and uncertainty of LiDAR-derived estimates of forest stand biomass," Remote Sensing of Environment, vol. 115, no. 2, pp. 636-649, 2011.

[85] A. A. Lindsey, J. D. Barton Jr., and S. R. Miles, "Field efficiencies of forest sampling methods," Ecology, vol. 39, no. 3, pp. 428-444, 1958.

[86] M. D. Bitencourt, H. N. de Mesquita Jr., G. Kuntschik, H. R. da Rocha, and P. A. Furley, "Cerrado vegetation study using optical and radar remote sensing: two Brazilian case studies," Canadian Journal of Remote Sensing, vol. 33, no. 6, pp. 468-480, 2007.

[87] J. M. Barbosa, I. Melendez-Pastor, J. Navarro-Pedreño, and M. D. Bitencourt, "Remotely sensed biomass over steep slopes: an evaluation among successional stands of the Atlantic Forest, Brazil," ISPRS Journal of Photogrammetry and Remote Sensing, vol. 88, pp. 91-100, 2014.

[88] H. Li, P. Mausel, E. Brondizio, and D. Deardorff, "A framework for creating and validating a non-linear spectrum-biomass model to estimate the secondary succession biomass in moist tropical forests," ISPRS Journal of Photogrammetry and Remote Sensing, vol. 65, no. 2, pp. 241-254, 2010.

[89] A. M. Wilson, J. A. Silander, A. Gelfand, and J. H. Glenn, "Scaling up: linking field data and remote sensing with a hierarchical model," International Journal of Geographical Information Science, vol. 25, no. 3, pp. 509-521, 2011.

[90] D. A. King, S. J. Davies, S. Tan, and N. S. M. Noor, “The role of wood density and stem support costs in the growth and mortality of tropical trees," Journal of Ecology, vol. 94, no. 3, pp. 670-680, 2006.

[91] D. M. D. Burger and W. B. C. Delitti, "Allometric models for estimating the phytomass of a secondary Atlantic Forest area of southeastern Brazil," Biota Neotropica, vol. 8, no. 4, pp. 131-136, 2008 . 
[92] S. A. Vieira, L. F. Alves, M. Aidar et al., "Estimation of biomass and carbon stocks: the case of the Atlantic Forest," Biota Neotropica, vol. 8, no. 2, pp. 21-29, 2008.

[93] B. W. Nelson, R. Mesquita, J. L. G. Pereira, S. G. A. de Souza, G. T. Batista, and L. B. Couto, "Allometric regressions for improved estimate of secondary forest biomass in the central Amazon," Forest Ecology and Management, vol. 117, no. 1-3, pp. 149-167, 1999.

[94] E. N. Broadbent, G. P. Asner, M. Peña-Claros, M. Palace, and M. Soriano, "Spatial partitioning of biomass and diversity in a lowland Bolivian forest: linking field and remote sensing measurements," Forest Ecology and Management, vol. 255, no. 7, pp. 2602-2616, 2008.

[95] T. Kajisa, T. Murakami, N. Mizoue, N. Top, and S. Yoshida, "Object-based forest biomass estimation using Landsat ETM+ in Kampong Thom Province, Cambodia," Journal of Forest Research, vol. 14, no. 4, pp. 203-211, 2009.

[96] B. M. Bolker, Ecological models and data in R, Princeton University Press, Princeton, NJ, USA, 2008.

[97] J. C. Ingram, T. P. Dawson, and R. J. Whittaker, "Mapping tropical forest structure in southeastern Madagascar using remote sensing and artificial neural networks," Remote Sensing of Environment, vol. 94, no. 4, pp. 491-507, 2005.

[98] G. M. Foody, M. E. Cutler, J. McMorrow et al., "Mapping the biomass of Bornean tropical rain forest from remotely sensed data," Global Ecology \& Biogeography, vol. 10, no. 4, pp. 379-387, 2001.

[99] D. Riaño, E. Chuvieco, J. Salas, and I. Aguado, "Assessment of different topographic corrections in Landsat-TM data for mapping vegetation types (2003)," IEEE Transactions on Geoscience and Remote Sensing, vol. 41, no. 5, pp. 1056-1061, 2003.

[100] Y. Gao and W. Zhang, "A simple empirical topographic correction method for ETM+ imagery," International Journal of Remote Sensing, vol. 30, no. 9, pp. 2259-2275, 2009.

[101] M. A. Lefsky, W. B. Cohen, S. A. Acker, G. G. Parker, T. A. Spies, and D. Harding, "Lidar remote sensing of the canopy structure and biophysical properties of Douglas-Fir Western Hemlock Forests," Remote Sensing of Environment, vol. 70, no. 3, pp. 339361, 1999.

[102] P. Köhler and A. Huth, "Towards ground-truthing of spaceborne estimates of above-ground life biomass and leaf area index in tropical rain forests," Biogeosciences, vol. 7, no. 8, pp. 2531-2543, 2010.

[103] J. Chave, C. Andalo, S. Brown et al., "Tree allometry and improved estimation of carbon stocks and balance in tropical forests," Oecologia, vol. 145, no. 1, pp. 87-99, 2005.

[104] J. R. Santos, C. C. Freitas, L. S. Araujo et al., "Airborne P-band SAR applied to the aboveground biomass studies in the Brazilian tropical rainforest," Remote Sensing of Environment, vol. 87, no. 4, pp. 482-493, 2003.

[105] D. H. Hoekman and M. J. Quiñones, "Land cover type and biomass classification using AirSAR data for evaluation of monitoring scenarios in the Colombian Amazon," IEEE Transactions on Geoscience and Remote Sensing, vol. 38, no. 2 I, pp. 685-696, 2000.

[106] J. P. Arroyo-Mora, G. A. Sánchez-Azofeifa, M. E. R. Kalacska, B. Rivard, J. C. Calvo-Alvarado, and D. H. Janzen, "Secondary forest detection in a Neotropical dry forest landscape using Landsat 7 ETM+ and IKONOS imagery," Biotropica, vol. 37, no. 4, pp. 497-507, 2005.

[107] D. A. Coomes, R. B. Allen, N. A. Scott, C. Goulding, and P. Beets, "Designing systems to monitor carbon stocks in forests and shrublands," Forest Ecology and Management, vol. 164, no. 1-3, pp. 89-108, 2002.

[108] G. C. Hurtt, R. Dubayah, J. Drake et al., "Beyond potential vegetation: combining lidar data and a height-structured model for carbon studies," Ecological Applications, vol. 14, no. 3, pp. 873883, 2004.

[109] A. C. Morel, S. S. Saatchi, Y. Malhi et al., "Estimating aboveground biomass in forest and oil palm plantation in Sabah, Malaysian Borneo using ALOS PALSAR data," Forest Ecology and Management, vol. 262, no. 9, pp. 1786-1798, 2011.

[110] S. Descloux, V. Chanudet, H. Poilvé, and A. Grégoire, "Coassessment of biomass and soil organic carbon stocks in a future reservoir area located in Southeast Asia," Environmental Monitoring and Assessment, vol. 173, no. 1-4, pp. 723-741, 2011.

[111] J. B. Drake, R. O. Dubayah, D. B. Clark et al., "Estimation of tropical forest structural characteristics, using large-footprint lidar," Remote Sensing of Environment, vol. 79, no. 2-3, pp. 305319, 2002.

[112] S. Eckert, H. R. Ratsimba, L. O. Rakotondrasoa, L. G. Rajoelison, and A. Ehrensperger, "Deforestation and forest degradation monitoring and assessment of biomass and carbon stock of lowland rainforest in the Analanjirofo region, Madagascar," Forest Ecology and Management, vol. 262, no. 11, pp. 1996-2007, 2011.

[113] D. Lu, P. Mausel, E. Brondízio, and E. Moran, "Relationships between forest stand parameters and Landsat TM spectral responses in the Brazilian Amazon Basin," Forest Ecology and Management, vol. 198, no. 1-3, pp. 149-167, 2004.

[114] C. Proisy, P. Couteron, and F. Fromard, "Predicting and mapping mangrove biomass from canopy grain analysis using Fourier-based textural ordination of IKONOS images," Remote Sensing of Environment, vol. 109, no. 3, pp. 379-392, 2007.

[115] I. da Silva Narvaes, A. de Queiroz da Silva, and J. R. dos Santos, "Evaluation of the interaction between SAR L-band signal and structural parameters of forest cover," in Proceedings of the IEEE International Geoscience and Remote Sensing Symposium (IGARSS '07), pp. 1607-1610, Barcelona, Spain, June 2007.

[116] M. Simard, V. H. Rivera-Monroy, J. E. Mancera-Pineda, E. Castañeda-Moya, and R. R. Twilley, "A systematic method for 3D mapping of mangrove forests based on Shuttle Radar Topography Mission elevation data, ICEsat/GLAS waveforms and field data: application to Ciénaga Grande de Santa Marta, Colombia," Remote Sensing of Environment, vol. 112, no. 5, pp. 2131-2144, 2008

[117] F. J. Ponzoni, L. S. Galvao, V. Liesenberg, and J. R. Santos, "Impact of multi-angular CHRIS/PROBA data on their empirical relationships with tropical forest biomass," International Journal of Remote Sensing, vol. 31, no. 19, pp. 5257-5273, 2010.

[118] J. E. Nichol and M. L. R. Sarker, "Improved biomass estimation using the texture parameters of two high-resolution optical sensors," IEEE Transactions on Geoscience and Remote Sensing, vol. 49, no. 3, pp. 930-948, 2011.

[119] L. R. Sarker and J. E. Nichol, "Improved forest biomass estimates using ALOS AVNIR-2 texture indices," Remote Sensing of Environment, vol. 115, no. 4, pp. 968-977, 2011.

[120] A. Luckman, J. Baker, T. M. Kuplich, F. Y. Corina da Costa, and C. F. Alejandro, "A study of the relationship between radar backscatter and regenerating tropical forest biomass for spaceborne SAR instruments," Remote Sensing of Environment, vol. 60, no. 1, pp. 1-13, 1997.

[121] D. H. T. Minh, T. le Toan, F. Rocca, S. Tebaldini, M. M. D’Alessandro, and L. Villard, "Relating P-band synthetic aperture radar 
tomography to tropical forest biomass," IEEE Transactions on Geoscience and Remote Sensing, vol. 52, no. 2, pp. 967-979, 2014.

[122] P. Ploton, R. Pélissier, C. Proisy et al., "Assessing aboveground tropical forest biomass using Google Earth canopy images," Ecological Applications, vol. 22, no. 3, pp. 993-1003, 2012.

[123] G. M. Foody and P. J. Curran, "Estimation of tropical forest extent and regenerative stage using remotely sensed data," Journal of Biogeography, vol. 21, no. 3, pp. 223-244, 1994.

[124] G. M. Foody, R. M. Green, R. M. Lucas, P. J. Curran, M. Honzak, and I. do Amaral, "Observations on the relationship between SIR-C radar backscatter and the biomass of regenerating tropical forests," International Journal of Remote Sensing, vol. 18, no. 3, pp. 687-694, 1997.

[125] D. S. Boyd, G. M. Foody, and P. J. Curran, "The relationship between the biomass of Cameroonian tropical forests and radiation reflected in middle infrared wavelengths $(3.0-5.0 \mu \mathrm{m})$," International Journal of Remote Sensing, vol. 20, no. 5, pp. 10171023, 1999.

[126] W. A. Salas, M. J. Ducey, E. Rignot, and D. Skole, "Assessment of JERS-1 SAR for monitoring secondary vegetation in Amazonia: I. Spatial and temporal variability in backscatter across a chrono-sequence of secondary vegetation stands in Rondonia," International Journal of Remote Sensing, vol. 23, no. 7, pp. 13571379, 2002.

[127] T. Neeff, L. V. Dutra, J. R. dos Santos, C. da Costa Freitas, and L. S. Araujo, "Tropical forest measurement by interferometric height modeling and P-band radar backscatter," Forest Science, vol. 51, no. 6, pp. 585-594, 2005.

[128] M. A. Castillo-Santiago, M. Ricker, and B. H. J. de Jong, "Estimation of tropical forest structure from SPOT-5 satellite images," International Journal of Remote Sensing, vol. 31, no. 10, pp. 27672782, 2010.

[129] M. L. Clark, D. A. Roberts, J. J. Ewel, and D. B. Clark, "Estimation of tropical rain forest aboveground biomass with smallfootprint LiDAR and hyperspectral sensors," Remote Sensing of Environment, vol. 115, no. 11, pp. 2931-2942, 2011.

[130] C. Baraloto, S. Rabaud, Q. Molto et al., "Disentangling stand and environmental correlates of aboveground biomass in Amazonian forests," Global Change Biology, vol. 17, no. 8, pp. 26772688, 2011.

[131] G. P. Asner and J. Mascaro, "Mapping tropical forest carbon: calibrating plot estimates to a simple LiDAR metric," Remote Sensing of Environment, vol. 140, pp. 614-624, 2014.

[132] M. L. R. Sarker, J. Nichol, B. Ahmad, I. Busu, and A. A. Rahman, "Potential of texture measurements of two-date dual polarization PALSAR data for the improvement of forest biomass estimation," ISPRS Journal of Photogrammetry and Remote Sensing, vol. 69, pp. 146-166, 2012. 

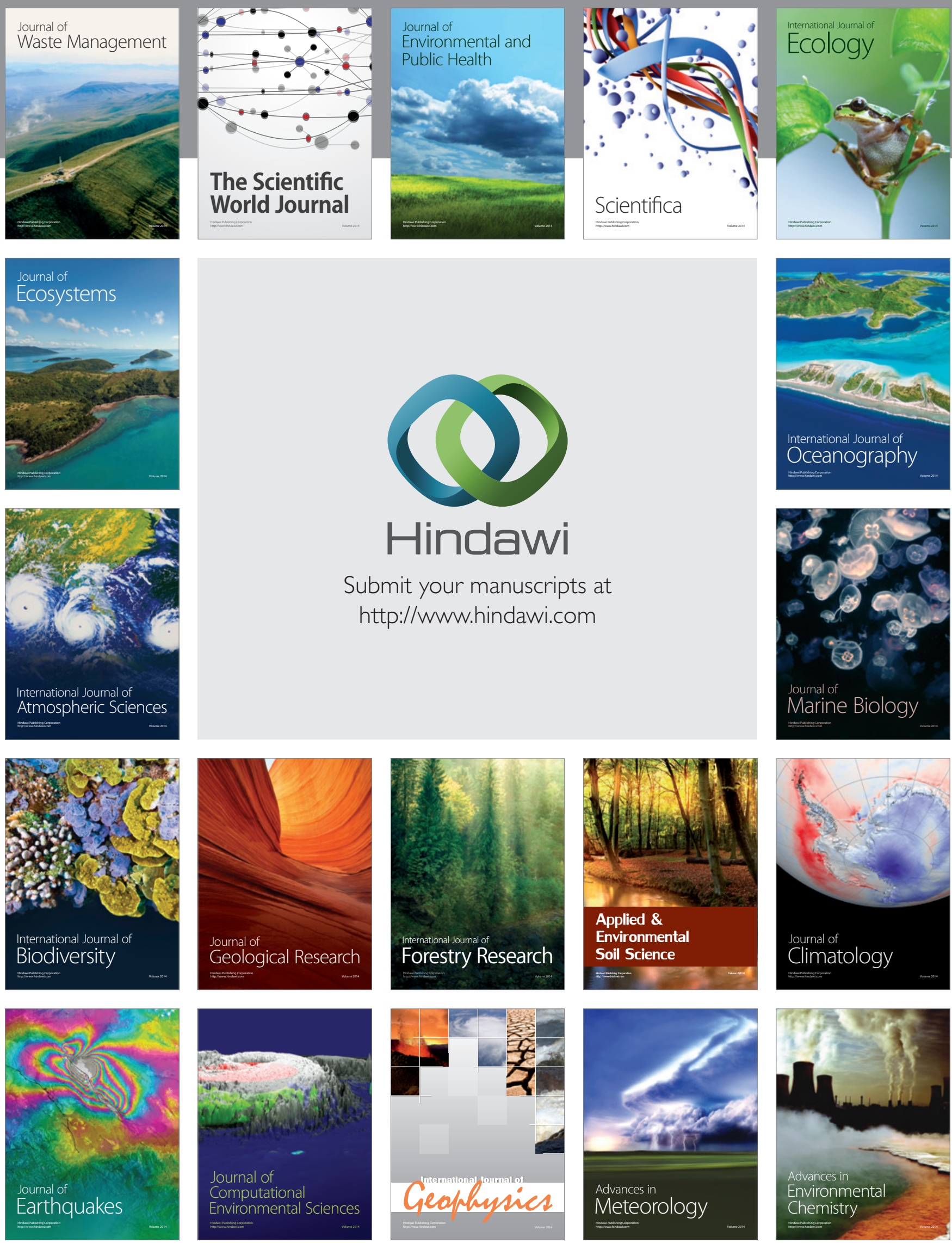